\title{
FUZZY LOGIC CONTROL FOR A PERMANENT MAGNET GENERATOR
} CONNECTED TO GRID

\author{
A. S. Zalat*, R. A. Amer** and G. A. Morsy** \\ * Egyptian Electricity Transmission Company (EETC) \\ **Electrical Engineering Dept., Faculty of Engineering, Menoufiya University, Shebin El-Kom, Egypt
}

\begin{abstract}
This paper presents modeling and simulation of direct driven permanent magnet generator (PMG) employed in wind energy conversion systems (WECS). The simulation of wind turbine and gridconnected-PMG is implemented under MATLAB-SIMLINK environment to study the system performance. In order to connect the PMG with the grid, set of full-scale converters are used. These converters consist of back-to-back voltage source inverters (generator side inverter and grid side inverter) connected through DC-link capacitor. This capacitor decouples the two inverters, allowing two separate control systems applied to them. In view of inverters control, firstly they are controlled using of proportional-integral (PI) control systems. The simulation results are obtained using this control strategy under different disturbances. Also, the design of fuzzy logic controllers (FLCs) instead of PI controllers is investigated. Simulation results show that the proposed FLC scheme is more effective for enhancing the stability of wind farms connected to grid during temporary network disturbances and randomly fluctuating wind speed compared with conventional PI controllers. This study introduces a better understanding of the real behavior and highlights the features of controlling PMGs in order to get better utilization of wind energy resources in the near future.

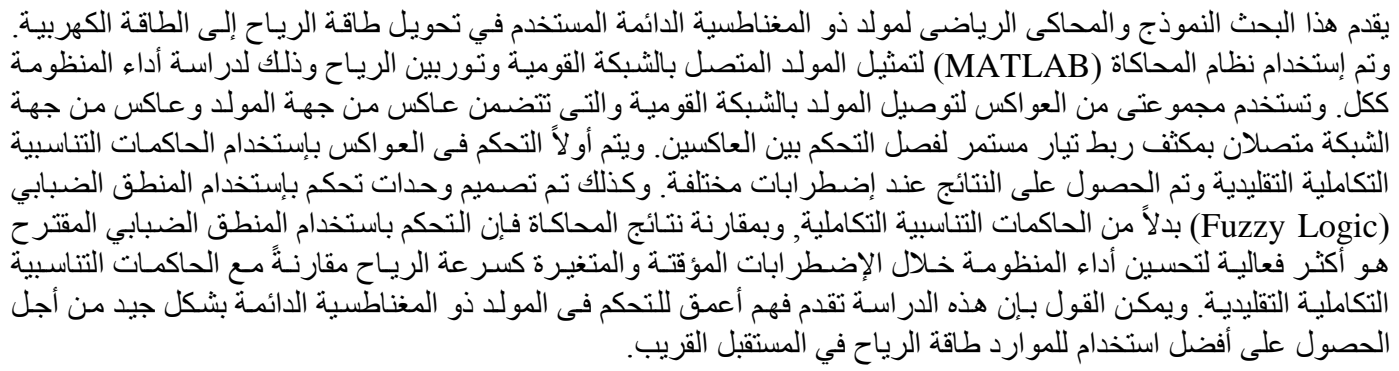

Keywords: Wind energy conversion system, grid connected PMG, PI control, Fuzzy logic control.

\section{INTRODUCTION}

Renewable energy sources including wind power generation introduce a well feasible solution to distributed power generation where electric grids are not available. At present, scenario of wind power has been emerged as the most viable source of economical electric power compared with the nonrenewable energy sources. So, wind power generation is considered as one of the most promising applications of renewable energy generation lies in the development of continuous power supply for remote villages that lack an economically feasible means of connecting to the main electric grid [1].

Control algorithm design for renewable energy production is a topic of great concern nowadays because of all the efforts around the reduction of greenhouse effects. Many countries have modified their energy production plans for the near future by developing green energy technologies [2].

Wind energy is the most rapid growth technology despite of wind is an irregular resource. Multiple types of generators are being used with wind turbines systems. Small wind turbine units are equipped with DC generators of rating up to fractional kilowatt [3]. The major types of AC generators that are possible candidates in wind turbine systems are as follows:

- Synchronous Generator (With external exciter),

- Squirrel-Cage rotor Induction Generator (SCIG),

- Wound-Rotor Induction Generator (WRIG),

- Doubly-Fed Induction Generator (DFIG) and

- Permanent Magnet Generator (PMG).

Induction generators (IGs) have been extensively used in commercial wind turbines. Asynchronous operation of IGs is considered an advantage for application in wind turbine systems, because it 
provides degree of flexibility when the wind speed is irregular or variable [3]. The IG based on SquirrelCage rotor (SCIG) is a very popular generator because of its low cost, mechanical simplicity and robust operation against disturbance and vibration. The IG based on wound-rotor is the doubly fed induction generator (DFIG) with both stator and rotor windings connected to the supply [4].

The variable-speed multi-pole permanent magnet generator (PMG) is considered to be a promising but not yet very popular wind turbine concept [5]. The advantages of such a PMG configuration including a gearless construction, an elimination of the excitation system, full controllability for grid interface and extracting maximum wind power and simplicity in accomplishing fault ride through and grid support [6]. Hence, the efficiency and reliability of a fullPWM-converter PMG is assessed to be higher than DFIG utilized in wind energy systems [7-8].

In this paper, modeling and simulation of gridconnected-PMG is investigated. To study the system performance under different disturbances, the simulation of the system is carried out under MATLAB-SIMLINK environment. The system is controlled using of proportional-integral (PI) controller as conventional control systems. Also, fuzzy logic controller (FLC) is proposed to enhance the system performance.

\section{Mathematical Modeling of the System}

In this section, the system components are mathematically modeled.

\subsection{PMG Model}

The dynamic model of the PMG is derived from the two phase synchronous reference frame; the qaxis is $90^{\circ}$ ahead of the d-axis with respect to the direction of rotation. The synchronization between the $d-q$ rotating reference frame and the three phase frame is maintained by using a phase locked loop (PLL) [9-10]. Figure (1) shows the d-q reference frame for a salient-pole generator (which is the same reference as the one used in a PMG) [11].

The dq0 Park's transformation is a mathematical transformation which aims to simplify the analysis of machinery models, and was first introduced by R. H. Park in 1929 [12]. In the three-phase, the phase quantities which include stator voltages, stator currents, and flux linkages are time varying quantities. By applying Park's transformation, the projection of the phase quantities onto a rotating two axes reference frame, the AC quantities are transformed to DC quantities which are time invariant. The dq-axes equivalent circuits of a PMG are shown in figure (2) [13].

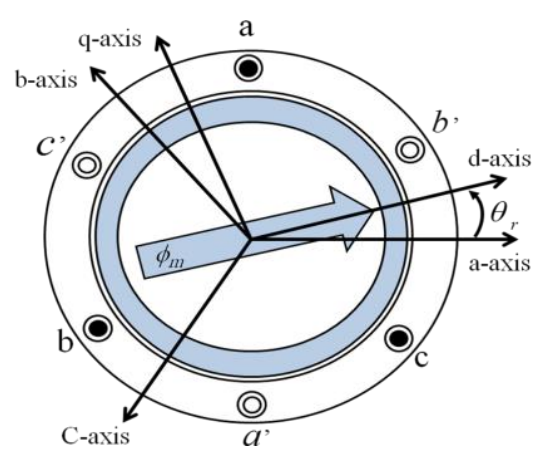

Figure (1) Cross-section view of the PMG

The voltages and torque functions of the PMG in the $d$-q-axes reference frame can be expressed as follows:

$$
\begin{aligned}
& v_{d s}=R_{s} i_{d s}+L_{d} \frac{d i_{d s}}{d t}-\omega_{e} L_{q} i_{q s} \\
& v_{q s}=R_{s} i_{q s}+L_{q} \frac{d i_{q s}}{d t}+\omega_{e} L_{q} i_{d s}+\omega_{e} \phi_{m} \\
& T_{e}=\left(\phi_{m} i_{q s}+\left(L_{d}-L_{q}\right) i_{d s} i_{q s}\right)
\end{aligned}
$$

where,

$\mathrm{v}_{\mathrm{ds}}$ and $\mathrm{v}_{\mathrm{qs}}$ stator $\mathrm{d}-\mathrm{q}$ axes voltages.

$i_{\mathrm{ds}}$ and $\mathrm{i}_{\mathrm{qs}}$ stator $\mathrm{d}-\mathrm{q}$ axes currents.

$\mathrm{R}_{\mathrm{s}}$ stator resistance.

$\mathrm{L}_{\mathrm{d}}$ and $\mathrm{L}_{\mathrm{q}} \mathrm{d}-\mathrm{q}$ axes inductances.

$\omega_{\mathrm{e}}$ electrical angular speed of the generator.

$\phi_{m}$ permanent magnetic flux.

Te electromagnetic torque.

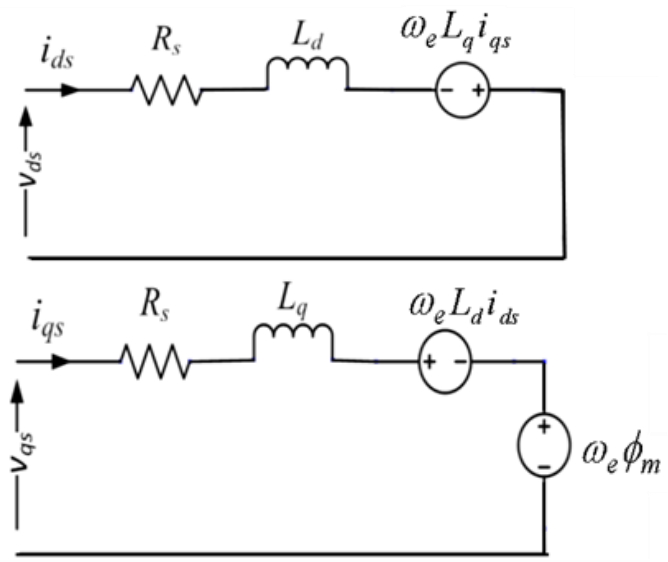

Figure (2) d-q axes equivalent circuits of a PMG

\subsection{Modeling of the DC Link}

A DC-link capacitor provides a short-term intermediate energy storage, which decouples the generator-side inverter and the grid-side inverter. Figure (3) shows the power flow in the DC link. If the losses are neglected, the DC link dynamics is expressed as:

$$
\begin{gathered}
P_{c}=P_{g}-P_{\text {net }} \\
V_{D C}=\sqrt{\frac{2}{C} \int P_{C} d t}
\end{gathered}
$$




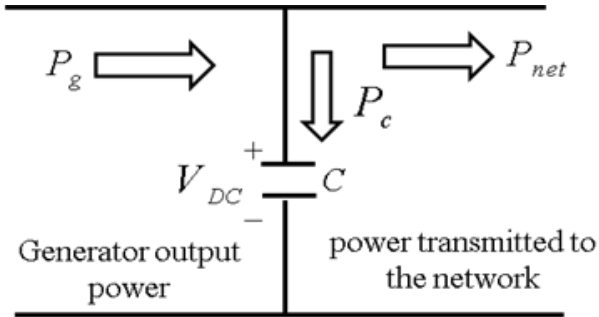

Figure (3) Power flow in the DC link

A constant DC-link voltage is required to ensure active power transmission from PMG terminal to the grid. Once there are any imbalances in powers $\mathrm{P}_{\mathrm{g}}$ and $\mathrm{P}_{\text {net }}$, the difference in power is stored in the DC-link capacitor and leads to an increase in the DC-link voltage.

\section{Control System Description}

In wind turbine setup, control system plays a crucial role to determine the efficiency. Without a good control system, a big portion of the power produced is wasted.

The control systems are separated into generatorside controller and grid-side controller as shown as figure (4) [14].

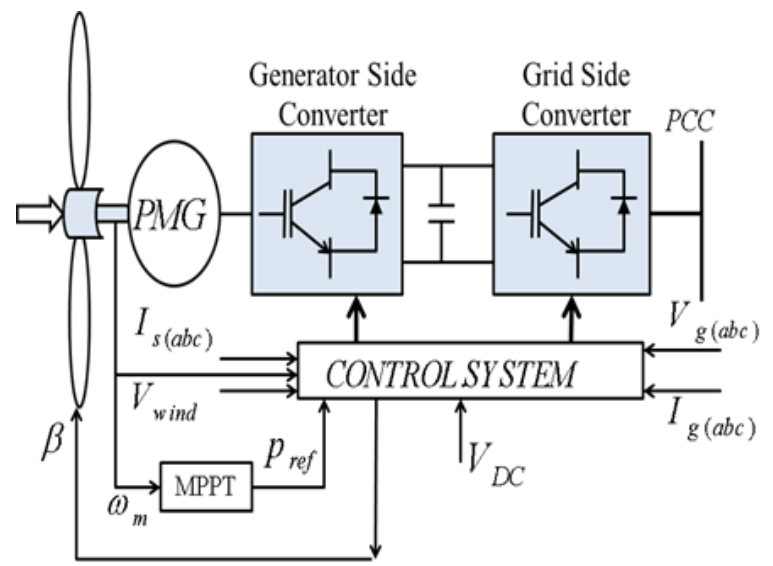

Figure (4) PMG based wind turbine configuration.

\subsection{Generator Side Controller}

\subsubsection{Field Oriented Control (FOC)}

The control system proposed to control wind turbine generator is Field Oriented Control (FOC). The control technique decouples the stator currents into: torque-producing current and magnetizing current. By decoupling these components, the torqueproducing current becomes independent from the other component as shown as figure (5). Also, Figure (6) shows the current controller for generator-side inverter [15].

The stator and rotor fluxes in PMG can be described in vectors. The electromagnetic torque produced through the interaction of the two fluxes.

$T e=\lambda_{r} * I_{s} * \sin (\delta)$

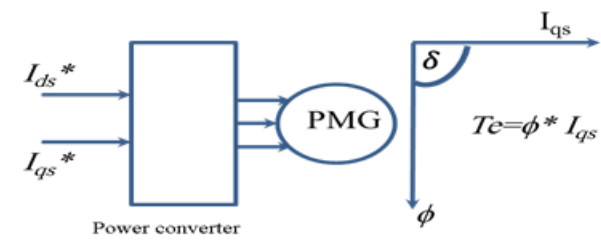

Figure (5) PMG operation

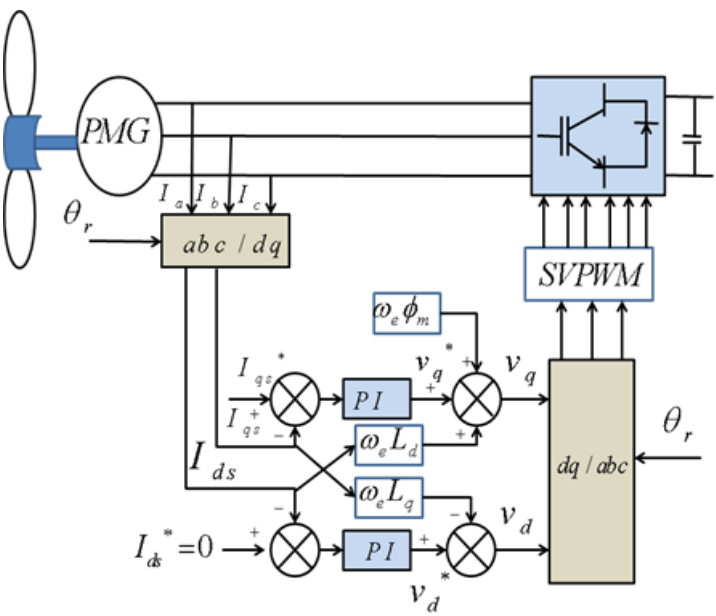

Figure (6) current control for generator-side inverter

The stator voltage components, synthesized by the generator side inverter, can be employed to govern the generator current components, $\mathrm{i}_{\mathrm{ds}}$, and $\mathrm{i}_{\mathrm{qs}}$ :

$$
\begin{aligned}
& v_{d s}=R_{s} i_{d s}+L_{d} \frac{d i_{d s}}{d t}-\omega_{e} L_{q} i_{q s} \\
& v_{q s}=R_{s} i_{q s}+L_{s} \frac{d i_{q s}}{d t}+\omega_{e} L_{s} i_{d s}+\omega_{e} \phi_{m}
\end{aligned}
$$

\subsection{Control of Grid-Side Inverter}

The grid side inverter is used to keep the DC link voltage constant and to regulate the active and reactive power. The DC link voltage is always changing by the incoming power from the wind turbine and output power to the grid. The control algorithm must sense the voltage variations to keep the voltage constant [16].

\subsubsection{Voltage Oriented Control}

In the normal operating conditions of the system, the grid currents are always negative. It's worth mentioned that there are many control techniques used to perform grid side inverter depending on the reference frame used to perform control strategies. Figure (7) shows the Block diagram of grid side inverter. If the reference frame is oriented along the supply voltage, the grid vector voltage is given by:

$$
v=v_{g d}+j \mathrm{O}
$$

The expressions of the active and reactive power can be expressed as [17]:

$$
\begin{gathered}
P_{g}=\left(v_{d g} i_{d g}\right) \\
Q_{g}=-\left(v_{d g} i_{q g}\right)
\end{gathered}
$$




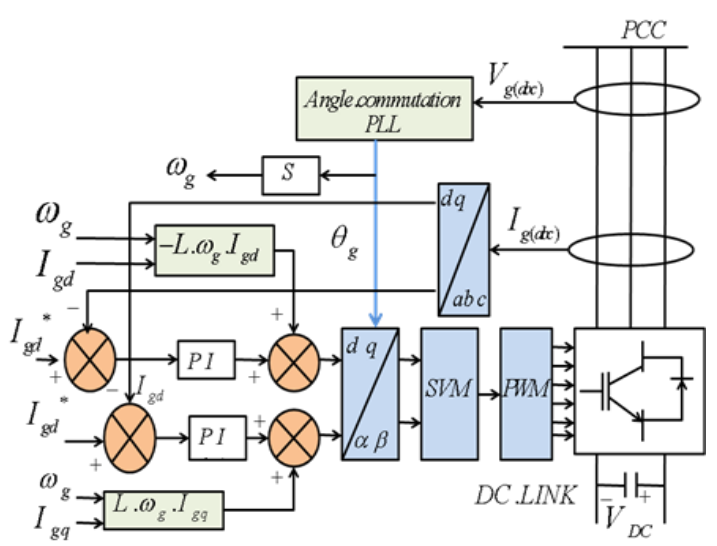

Figure (7) Block diagram of grid side inverter

The dynamic model of the grid connection, in reference frame rotating synchronously with the grid voltage, is given as follows [18]:

$$
\begin{aligned}
& v_{g d}=v_{i d}-i_{g d} R_{g}-L_{g} \frac{d i_{g d}}{d t}+i_{g q} \omega_{g} L_{g} \\
& v_{g q}=v_{i q}-i_{g q} R_{g}-L_{g} \frac{d i_{g q}}{d t}+i_{g d} \omega_{g} L_{g}
\end{aligned}
$$

where, $L_{g}$ and $R_{g}$ are the grid inductance and resistance, respectively. $v_{i d}$ and $v_{i q}$ are the inverter voltage components.

\section{4 .Maximum Power Point Tracking Methodology}

To maximize the use of wind energy when the wind speed is below the rated speed, the maximum power point tracking (MPPT) of the system is necessary. The MPPT is realized by controlling the inverter which is connected to the generator. The control is easy to understand but hard to achieve due to the need to know the exact wind speed from wind turbine characteristics.

\subsection{MPPT Methods}

The MPPT control strategy is proposed based on the theory of the conventional power feedback control and Hill Climb Searching (HCS) control. According to equation (14), the maximum power of the wind turbine $\mathrm{p}_{\max }$ is a cubic function of the generator speed [19]:

$p_{\max }=\frac{\rho \pi R^{5} C_{p \max } \omega_{o p t}{ }^{3}}{2 \lambda_{\text {opt }}{ }^{3}}=k_{\text {opt }} \omega_{o p t}{ }^{3}$

where, $k_{\text {opt }}$ is a constant determined by the wind turbine characteristics.

Therefore, the optimal current given (OCG) MPPT control strategy is proposed here based on the PMG model for improving the traditional power feedback method. $i_{d}=0$ current control strategy is commonly used for the vector control for the PMG due to the simplicity and effectiveness.

$T_{e}=\phi_{m} i_{q s}$

Permanent magnet flux is constant. Therefore, the PMG can obtain the optimum torque by giving the optimum $i_{q s}$. Furthermore, the maximum power point can be achieved when the torque versus speed meets the optimal curve shown in Figure (8). In other words, the MPPT can be realized when the optimal $i_{q s}$ is given.

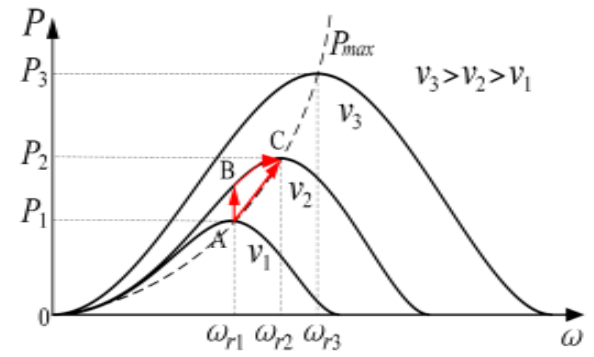

(a)

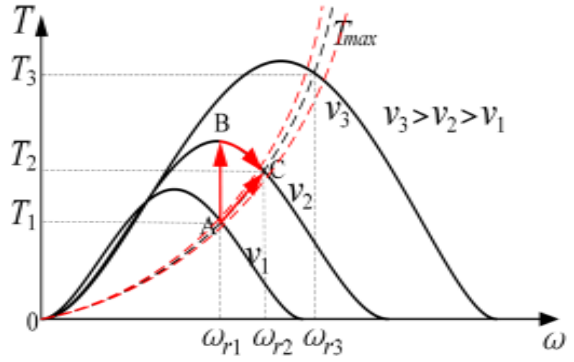

(b)

Figure (8) Wind turbine characteristics

(a) Power versus rotor speed.

(b) Torque versus rotor speed.

\subsection{Estimation of $\mathbf{T}_{\text {loss }}$}

$T_{\text {loss }}$ can be procured based on the theory of dichotomy according to the characteristics of the PMG.

The loss torque can be divided as:

$T_{\text {loss }}=T_{\text {loss_fe }_{\_}}+T_{\text {loss_m }_{\text {m }}}+T_{\text {loss_s }}$

The iron loss mainly varies along with the generator speed, so the iron loss torque $T_{\text {loss_fe, }}$, which equals iron loss divided by speed, remains relatively constant. The mechanical loss and the stray loss only account for a small percentage of the total losses, thus the mechanical loss torque $T_{\text {loss } \_}$and the stray loss torque $T_{\text {loss_S }_{S}}$ can be regarded as constant values. Therefore, the loss torque $T_{\text {loss }}$ basically remains constant in operation.

Figure (9) shows the flow chart of the $T_{\text {loss }}$ estimation algorithm.

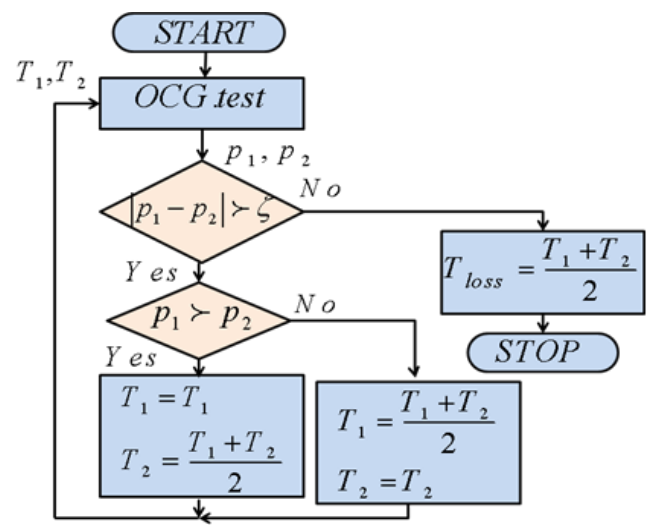

Figure (9) Flow chart of $T_{\text {loss }}$ estimation algorithm 


\subsection{Perturb and Observe ( $P$ and $O)$ Technique or Hill Climb Searching (HCS)}

Hill climb searching (HCS) or perturbation and observation ( $\mathrm{P}$ and $\mathrm{O}$ ) control is usually used for the peak power of the wind turbine that will maximize the extracted energy. This control efforts to climb the $\mathrm{P}_{\mathrm{m}}\left(\omega_{\mathrm{m}}\right)$ curve in the direction of increasing $\mathrm{P}_{\mathrm{m}}$, by varying the rotational speed periodically with a small incremental step in order to reduce the oscillation around the MPP. The (P and $\mathrm{O}$ ) algorithm compares the power previously delivered after one disturbance as shown as figure (10).

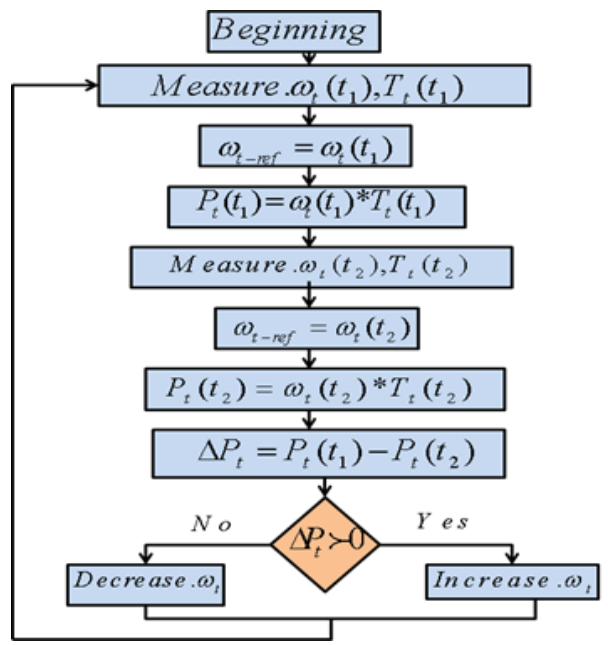

Figure (10) Flowchart of the (P and O) method

Under these conditions, the tracker seeks the MPP permanently. At specified wind speed, the desired mechanical power is the solution of the nonlinear equation given by:

$\frac{d P_{m}}{d \omega_{m}}=0$

In this algorithm, there is a trade-off between the rate of response and the amount of oscillations under steady state conditions. To vanquish this trade-off, the step size of varying amplitude can be applied. The step-size amplitude can be determined according to power variations based on the previously applied disturbance. Therefore, larger step-size amplitude is selected when power is far from MPP due to the larger magnitude of $\mathrm{P}_{\mathrm{m}}\left(\mathrm{x}_{\mathrm{m}}\right)$ slope and small amplitude is selected when power is close to MPP as shown as figure (11) [20- 22].

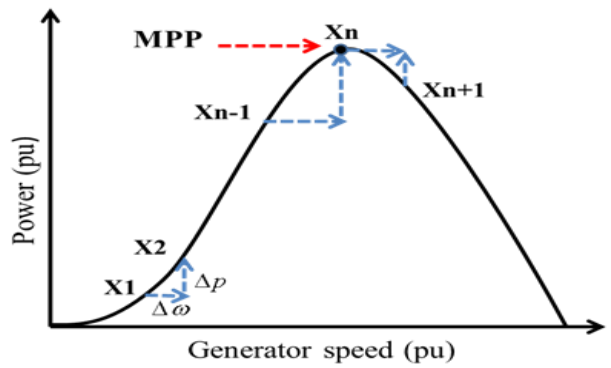

Figure (11) Principle of the P\&O MPPT

Figure (12) shows the hill climb search control of wind energy conversion system. Figure (13) shows the maximum power point tracking with $(\mathrm{P}$ and $\mathrm{O})$ control when illumination changes from $12 \mathrm{~m} / \mathrm{s}$ to 9 $\mathrm{m} / \mathrm{s}$.

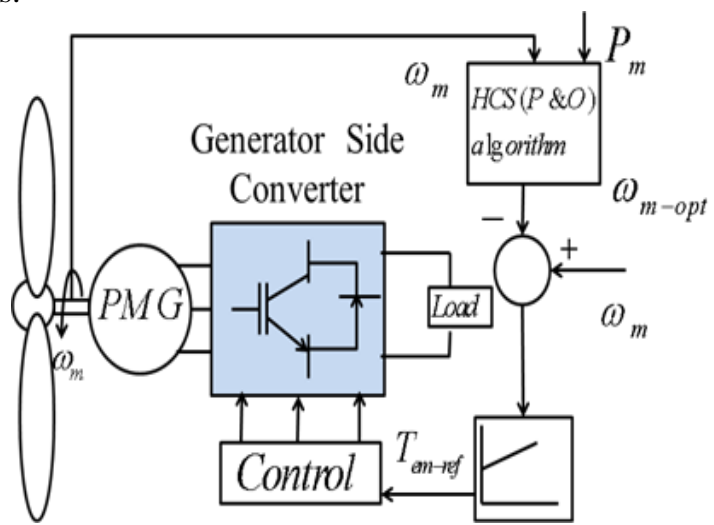

Figure (12) Hill Climb search control of wind energy conversion system
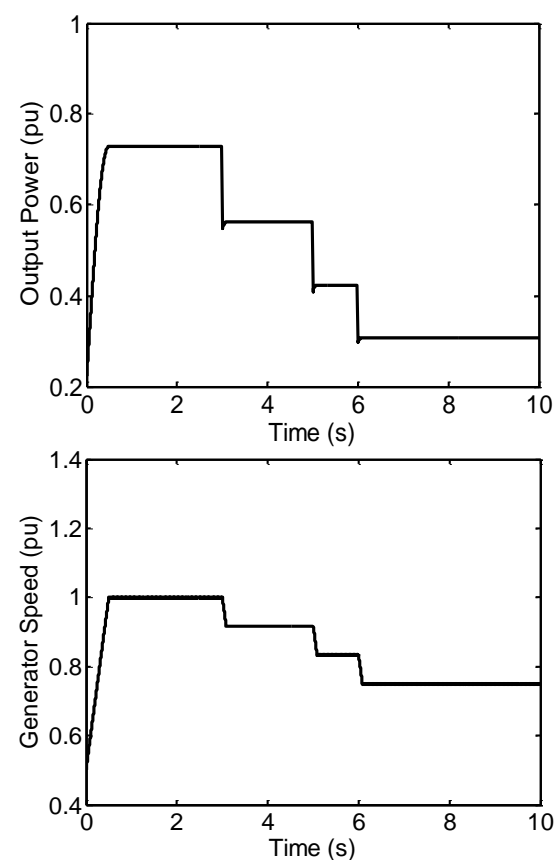

Figure (13) MPPT with (P and O) control when illumination changes from $12 \mathrm{~m} / \mathrm{s}$ to $9 \mathrm{~m} / \mathrm{s}$

Figure (14) shows the maximum power point tracking with $(\mathrm{P}$ and $\mathrm{O})$ control when increasing changes from $9 \mathrm{~m} / \mathrm{s}$ to $12 \mathrm{~m} / \mathrm{s}$. 

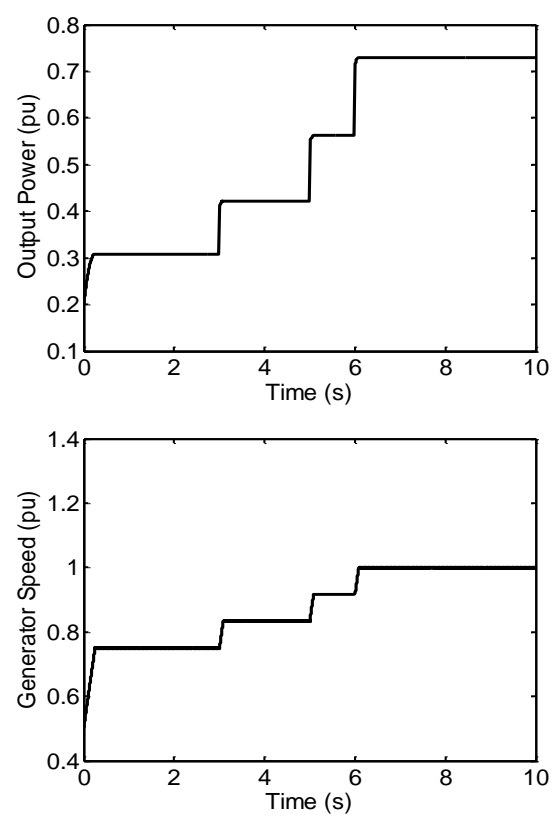

Figure (14) Maximum power point tracking with (P and O) control when increasing changes from $9 \mathrm{~m} / \mathrm{s}$ to $12 \mathrm{~m} / \mathrm{s}$.

\subsection{Power signal feedback (PSF)}

Proposed MPPT method requires the knowledge of the wind turbine and maximum power curve which can be obtained from simulations [23]. Then, the data points for maximum turbine power and the corresponding wind turbine speed must be recorded in a lookup table.

The PSF control method regulates the turbine power to maintain it to an optimal value, so that the power coefficient $\mathrm{Cp}$ is always at its maximum value corresponding to the optimal tip speed ratio as shown in figure (15) and figure (16).

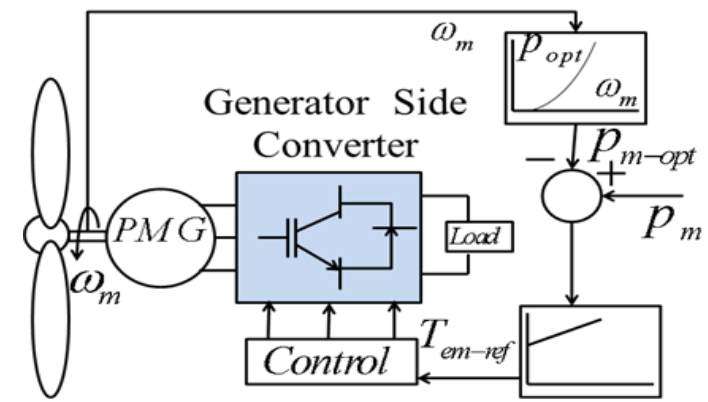

Figure (15) Power signal feedback control of wind energy conversion system

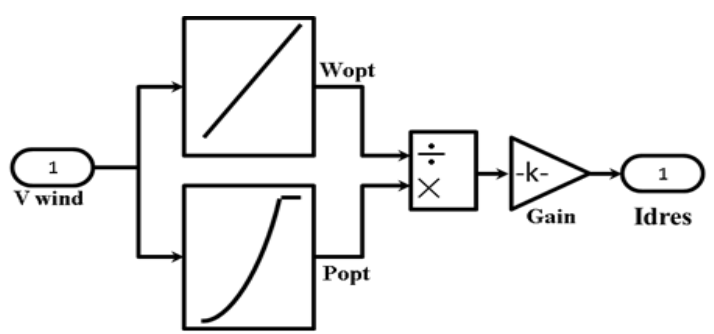

Figure (16) Power signal feedback method

\section{Fuzzy Logic Controller}

As shown in Fig. (17), the FLC system consists of three components. They are fuzzification, the rule base, and defuzzification. Fuzzification, the first component of the FLC, converts the exact inputs to fuzzy values. These fuzzy values are sent to the rulebase unit and processed with fuzzy rules, and then these derived fuzzy values are sent to the defuzzification unit [24]. In this unit, the fuzzy results are converted to exact values using center of area method. The fuzzy controller is characterized as follows:

1. Three fuzzy sets for each input and outputs: N, ZE, and $P$.

2. Triangular membership functions for simplicity.

3. Fuzzification using continuous universe of discourse.

4. Implication using sugeno's 'min' operator.

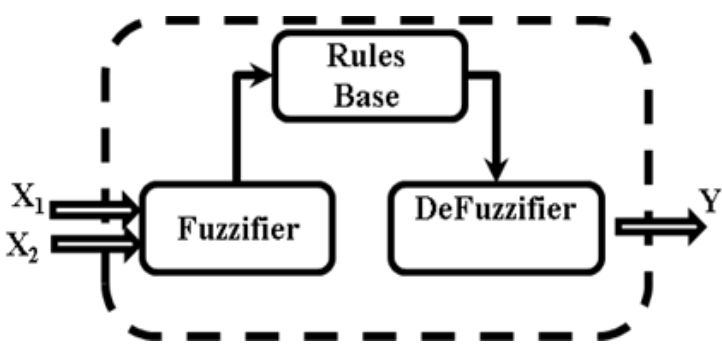

Figure (17) Basic configuration of a FLC

Fuzzy control has emerged one of the most active and fruitful areas of research especially in industrial processes which do not rely upon the conventional methods because of lack of quantitative data regarding the input and output relations. Fuzzy logic rules are simple and do not require precise control algorithm. Fuzzy logic systems are suitable for approximate reasoning.

Figure shows (18) the input membership functions of Fuzzy Logic Controller. Table (1) shows the Rules of FLC.

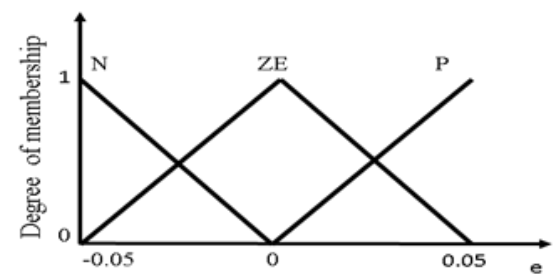

(a)

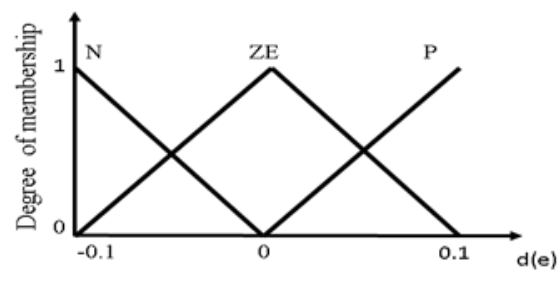

(b)

Figure (18) Input membership functions of FLC 
Table (1) Rules of FLC

\begin{tabular}{|c|c|c|c|c|}
\hline & \multicolumn{4}{|c|}{ Error(e) } \\
\hline \multirow{4}{*}{ 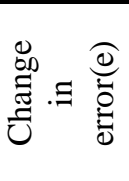 } & & $\mathrm{N}$ & ZE & $\mathrm{P}$ \\
\hline & $\mathrm{N}$ & $\mathrm{ZE}$ & $\mathrm{N}$ & $\mathrm{ZE}$ \\
\hline & $\overline{Z E}$ & $\mathrm{~N}$ & ZE & ZE \\
\hline & $\mathrm{P}$ & ZE & $\mathrm{P}$ & $\mathrm{N}$ \\
\hline
\end{tabular}

The generator side controller has been used to track the maximum power generated from WT through controlling the rotational speed of the turbine using FLC. The PMG has been controlled in indirect-vector field oriented control technique and its speed reference has been obtained from FLC. In the grid side inverter, active and reactive power control has been achieved by controlling $\mathrm{q}$-axis and d-axis grid current components respectively. The d-axis grid current is controlled to be zero for unity power factor and the q-axis grid current is controlled to deliver the power flowing from the DC-link to the grid.

\section{MODELING AND SIMULATION RESULTS}

\subsection{Simulated Model Description}

Simulations are carried out in MATLAB/Simulink software for 2 MW PMG-based wind power system to verify the effectiveness of the proposed strategy. Parameters of the wind turbine and PMG are listed in appendices A and B respectively.

\subsection{System model}

The system SIMULINK model is illustrated in figure (19). This model shows the wind turbine and the driven PMG connected to grid mathematical model.

\subsection{SIMULATION RESULTS}

In this paper, the performance and the effectiveness of the proposed control strategy are evaluated under various operating regimes of the PMG wind system (shown in figure (4)) with parameters given in Appendix B. Simulation study has been carried out using MATLAB-SIMULINK for comparing the graphs of conventional PI and FLC. Two cases studies are considered and described as follows: 3-phase short circuit and one line outage for $100 \mathrm{msec}$.

After comparing the graphs of conventional PI and fuzzy logic controller as shown in Figure (2021 ) it is clear that system performance with fuzzy logic controllers has small overshoot and fast response compared to conventional PI controllers.

The simulation results are obtained when using this control strategy under different disturbances. Also, the design FLCs instead of PI controllers is investigated. Simulation results show that the proposed FLC scheme is more effective for enhancing the stability of wind farms connected to grid during temporary of network disturbances and randomly fluctuating wind speed compared with that of a conventional PI controller.

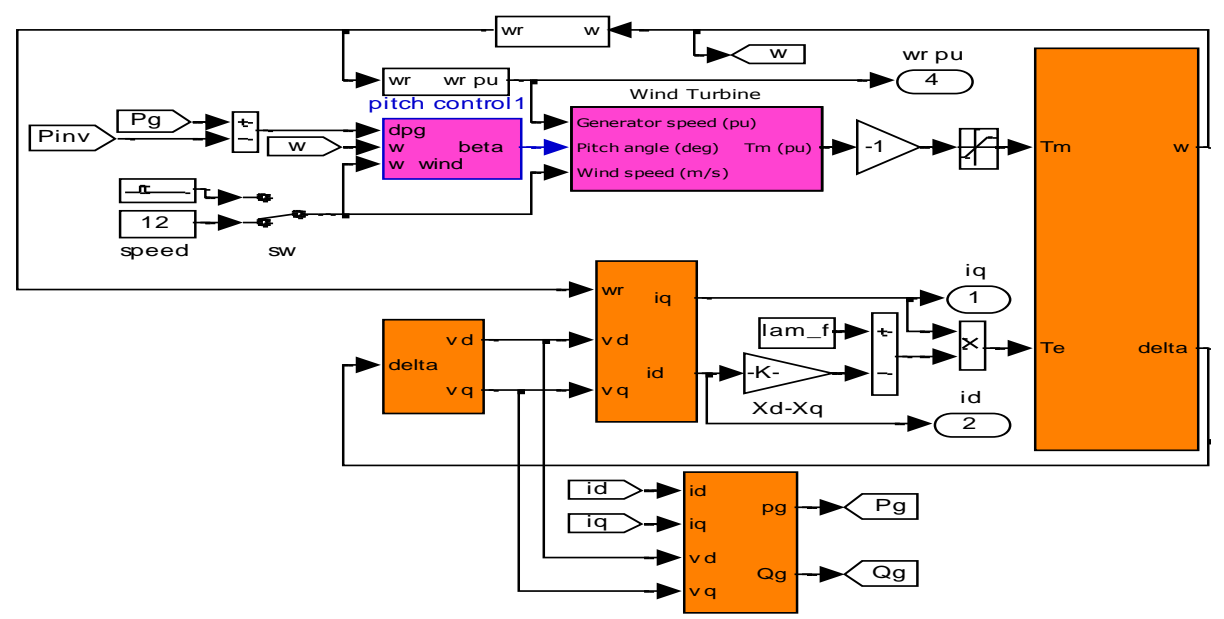

Figure (19) SIMULINK model of the system
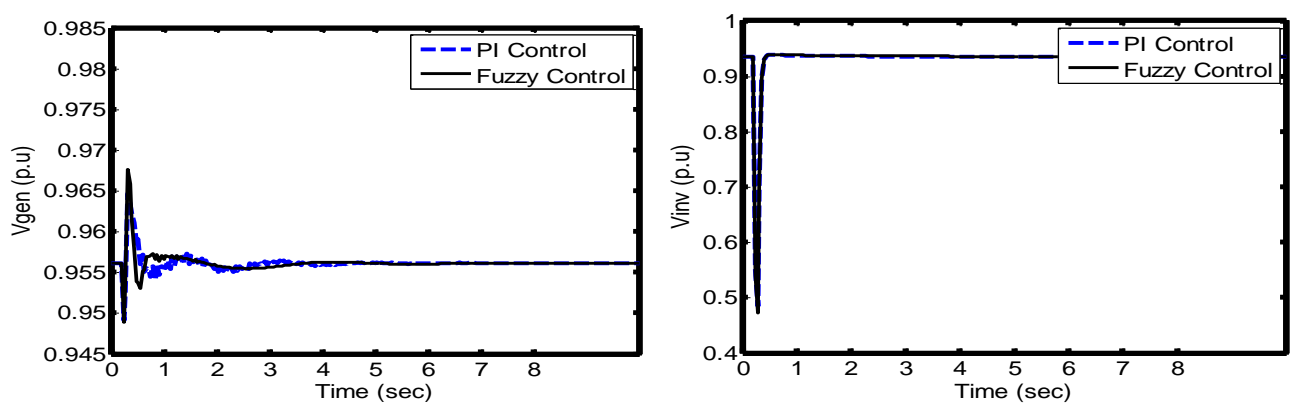

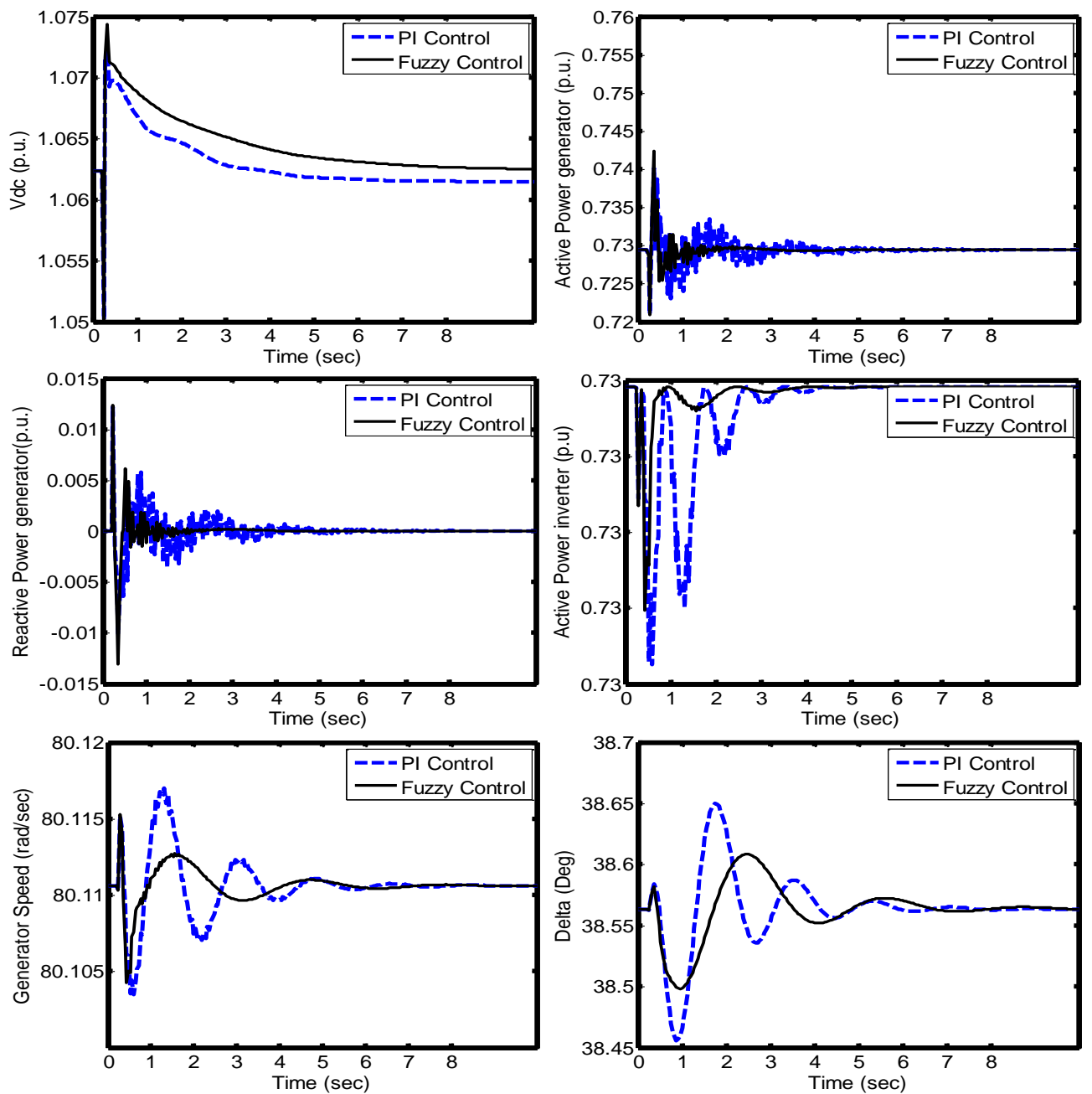

Figure (20) System transient response to a 3-phase short circuit for $100 \mathrm{~ms}$
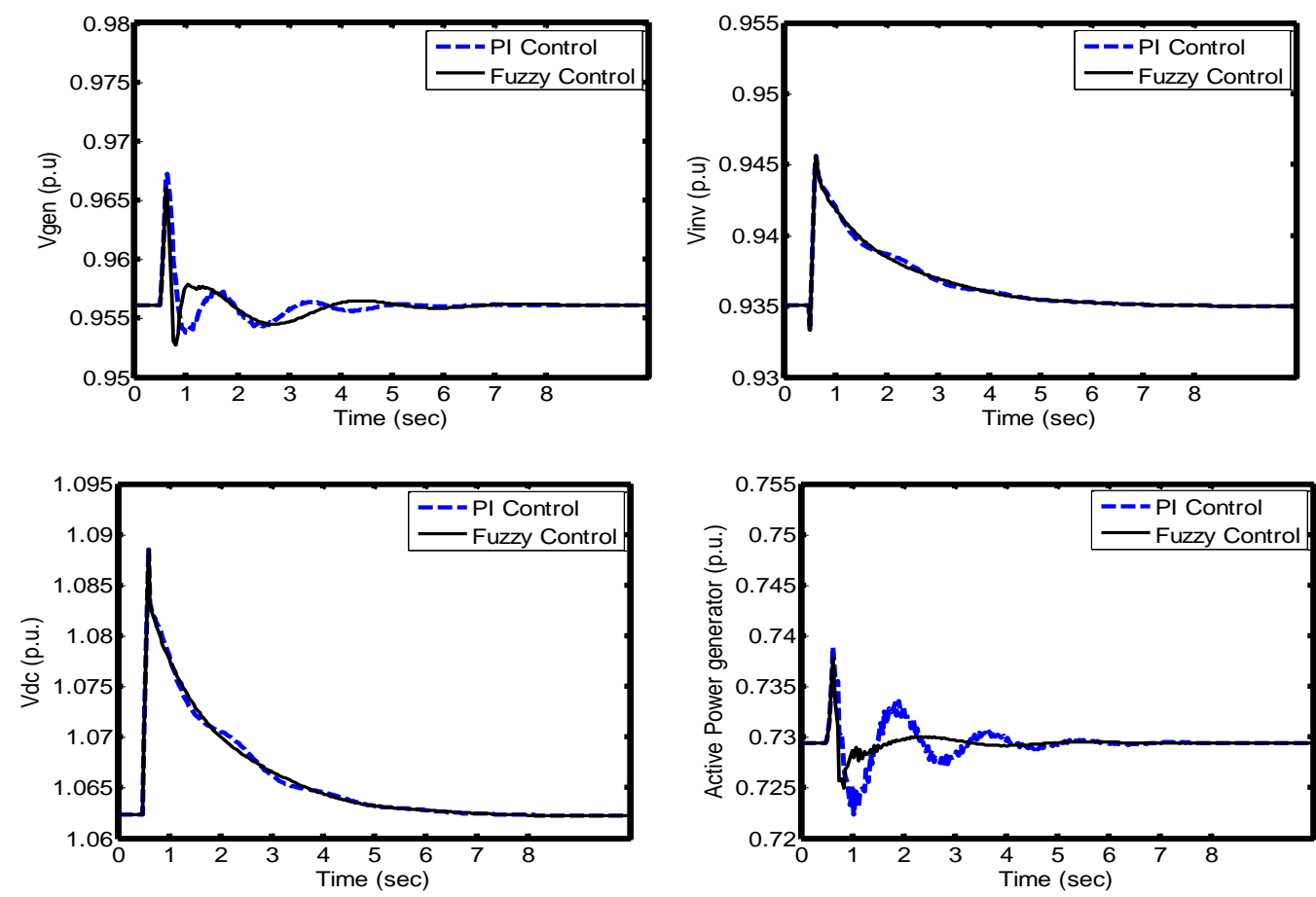

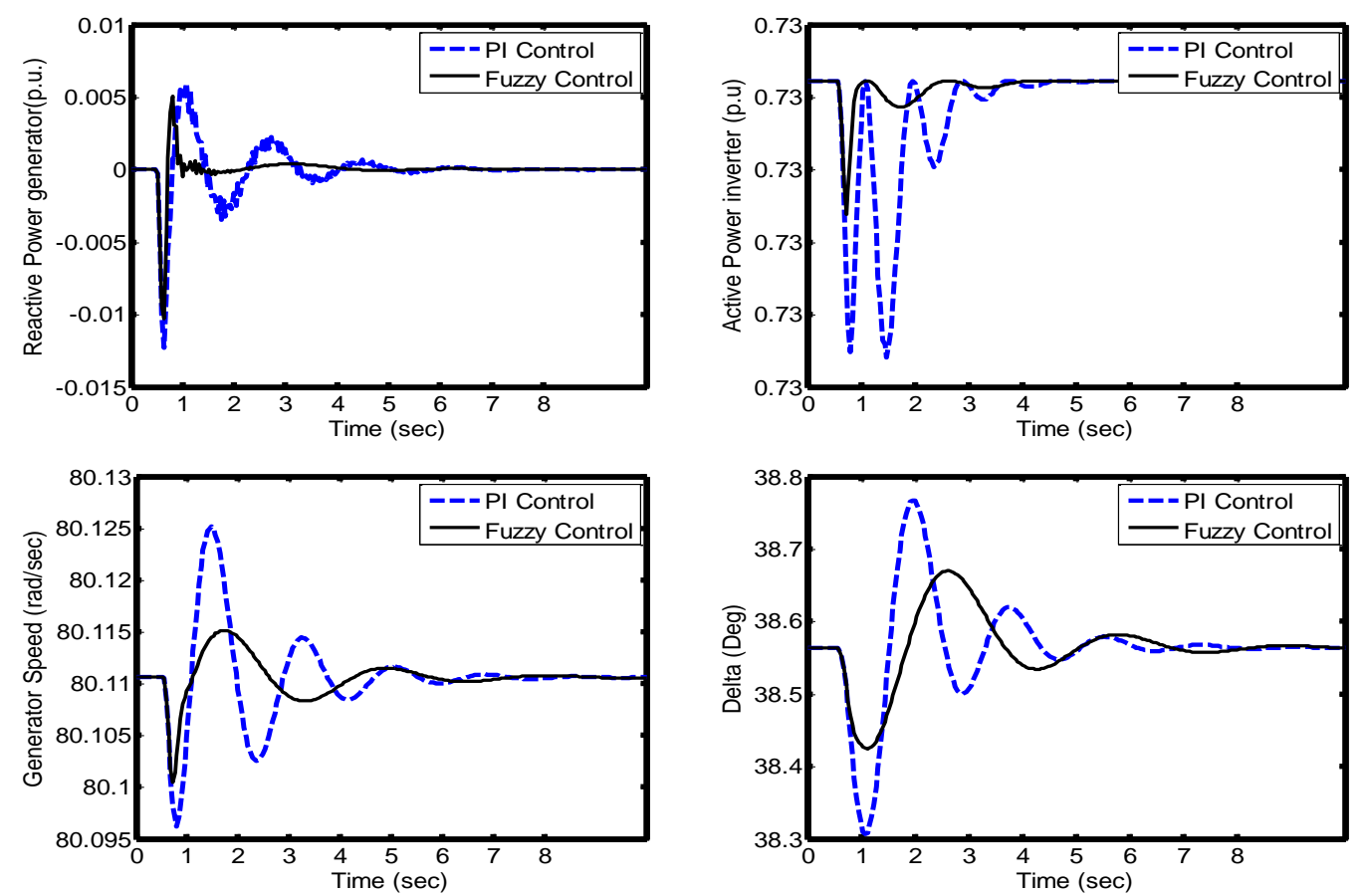

Figure (21) System transient response to a one line outage for $100 \mathrm{~ms}$

\section{CONCLUSION}

In this paper, wind energy conversion system made with a permanent magnet generator (PMG) has been presented. This system is constituted of a PMG with the rotor connected directly to the turbine while the stator is connected to the grid through AC-DC-AC converters. The control of the stator side inverter is designed based on either conventional PI or fuzzy logic controller (FLC). The available MPPT algorithms for wind energy systems have been discussed and reviewed in this paper. The simulation results show that, FLC scheme is more effective for enhancing the stability of wind farms connected to grid during temporary and sudden network disturbances compared with that of a conventional PI controller.

\section{REFERENCES}

[1] G. Klempner and I. Kerszenbaum, "Operation and Maintenance of Large Scale TurboGenerators", John Wiley \& Sons, 2004.

[2] L. A. Barroso, H. Rudnick, F. Sensfuss and P. Linares, "The Green Effect" IEEE Power \& Energy, Vol. 8, No. 5, IEEE Pes, EUA, pp. 22-35, 2010.

[3] S. R. Bull, "Renewable energy today and tomorrow", proc. IEEE, Vol. 89, No. 8, pp. 12161226, August. 2001.

[4] F. S. Gunawan, "A Study of the Field-Oriented Control of a Permanent Magnet Synchronous Machine With and Without Position Sensor", M.Sc. Thesis Columbus $(\mathrm{OH})$ : The Ohio State University; 1997.
[5] V. Oghafy and H. Nikkhajoei, "Maximum power extraction for a wind-turbine generator with no wind speed sensor", in Proceedings on IEEE, Conversion and Delivery of Electrical Energy in the 21st Century, pp. 1-6, 2008.

[6] G. Michalke, A. D. Hansen and T. Hartkopf, "Control strategy of a variable speed wind turbine with multipole permanent magnet synchronous generator", European Wind Energy Conference and Exhibition, Milan (IT), 7-10 May, 2007.

[7] H. Li, Z. Chen, H. Polinder, "Optimization of multibrid permanent-magnet wind generator systems", IEEE Transactions on Energy Conversion pp. 82-92, March, 2009.

[8] D. J. Bang, H. Polinder, G. Shrestha and J. A. Ferreira, "Review of generator systems for directdrive wind turbines", European Wind Energy Conference \& Exhibition, Belgium, 31 March-3 April, 2008.

[9] A. E. Fitgerald, J. C. Kingsley and S. D. Umans, "Electric Machinery", New York, McGraw-Hill, 1990.

[10] H. M. Farh and A. M. Eltamaly, "Fuzzy Logic Control of Wind Energy Conversion System", Renewable Sustainable Energy 5, 023125, doi: 10.1063/1.4798739, 2013.

[11] I. Erlich, U. Bachmann, "Grid code requirements concerning connection and operation of wind turbines in Germany", IEEE Power Eng Soc General Meet 2, pp. 1253-1257, 2005. 
[12] L. Wang, C. Singh and A. Kusiak, "Wind power systems applications of computational intelligence", Springer, Berlin, 2010.

[13] D. Rekioua, T. Rekioua, K. Idjdarene and A. Tounzi, "An approach for the modeling of an autonomous induction generator taking into account the saturation effect", Int J. Emerg Electr Power Syst 4(1), pp.1-25, 2005.

[14] M. O. Mora, "Sensorless Vector Control of PMSG for Wind Turbine applications", M.Sc. thesis, Institute of Energy Technology Allborg University; 2009.

[15] M. A. Abdullah, A. H. M. Yatim and C. W. Tan, "A study of maximum power point tracking algorithms for wind energy system", Procedings of $1^{\text {st }}$ IEEE Conference on Clean Energy and Technology CET, 2011.

[16] Q. Huynh, F. Nollet, N. Essounbouli and A. Hamzaoui, "Fuzzy control of variable speed wind turbine using permanent magnet synchronous machine for stand-alone system", Sustainability in Energy and Buildings: Proceedings of the 3rd International Conference in Sustainability in Energy andBuildings (SEB 11), vol. 12. Springer Verlag, 2012.

[17] B. Wu, Y. Lang, N. Zargari and S Kouro "Power Conversion and Control of Wind Energy Systems", Hoboken, NJ: Wiley, 2011.

[18] M. Chinchilia, S. Arnaltes and J. Burgos "Control of permanent-magnet generator applied to variable-speed wind-energy systems connected to the grid", IEEE Trans Energy Convers, 21(1), 2006.

[19] D. M. Vilathgamuwa, S. D. Jayasinghe and U. K. Madawala, "Space vector modulated cascade multi-level inverter for PMSG wind generation systems", Proceedings of IEEE Annual Conference of Industrial Electronics, Porto, Portugal, pp. 4600-4605, November 2009.

[20] F. Iov, A. D. Hansen, P. Sorensen and F. Blaabjerg, "Wind turbine blackest in Matlab/Simulink", Research Project, Institute of Energy Technology, Alborg University, March 2004.

[21] A. Mullane, G. Lightbody, R. Yacamini, "Adaptive control of variable speed wind turbines", University College Cork, Ireland, 2001.

[22] A.Kulka, "Pitch and Torque Control of Variable Speed Wind Turbines", M. S. thesis, Chalmers University of Technology, Goteborg, Sweden 2004.

[23] K. C. Divya, J. Stergaard, "Battery energy storage technology for power systemsan overview", Electric Power System Research 79: pp. 511-520, 2009.

[24] M. El-Mokadem, V. Courtecuisse, C. Saudemont, B. Robyns and J. D. February, "Fuzzy Logic Supervisor-Based Primary
Frequency Control Experiments of a VariableSpeed Wind Generator", IEEE Transactions on Power Systems, Vol. 24, No. 1, 2009.

\section{Appendix A}

\section{Specification of Wind Turbine}

A generic equation is used to model $\mathrm{C}_{\mathrm{p}}(\mathrm{k}, \mathrm{b})$ based on the modeling turbine characteristics as :

$$
\begin{aligned}
& c_{p}=c_{1}\left(c_{2} \frac{1}{\alpha}-c_{3} \beta-c_{4} \beta^{x}-c_{5}\right) e^{-c 6 \frac{1}{\alpha}} \\
& \frac{1}{\alpha}=\frac{1}{\lambda+.08 \beta}-\frac{.035}{1+\beta^{3}}
\end{aligned}
$$

where, $\mathrm{c}_{1}=0.5176, \mathrm{c}_{2}=116, \mathrm{c}_{3}=0.4, \mathrm{c}_{4}=5, \mathrm{c}_{5}=21$, and $\mathrm{c}_{6}=0.0068$.

\section{Appendix B}

\section{Parameters of Simulation Models}

Table (B.1) PMG configuration parameters

\begin{tabular}{|c|c|}
\hline PMG parameter & Value \\
\hline Stator resistance $\left(\mathrm{R}_{\mathrm{s}}\right)$ & 0.0001 p.u. \\
\hline Stator direct inductance $\left(\mathrm{L}_{\mathrm{d}}\right)$ & 0.95 p.u. \\
\hline Stator quadrature inductance $\left(\mathrm{L}_{\mathrm{q}}\right)$ & 1.0 p.u. \\
\hline Permanent magnet flux $\left(\phi_{m}\right)$ & 1.2 p.u. \\
\hline Inertia of the whole system $(\mathrm{J})$ & 0.0873 \\
\hline Friction factor $(\mathrm{F})$ & 0 \\
\hline
\end{tabular}

Table (B.2) DC bus and grid parameters

\begin{tabular}{|c|c|}
\hline DC bus and grid parameters & Value \\
\hline DC-Link voltage $\left(\mathrm{V}_{\mathrm{dc}}\right)$ & 0.0001 p.u. \\
\hline Capacitance of the DC link $\left(\mathrm{C}_{\mathrm{dc}}\right)$ & 1.0 p.u. \\
\hline Grid frequency $(\mathrm{F})$ & 1.0 p.u. \\
\hline Grid resistance $\left(\mathrm{R}_{\mathrm{g}}\right)$ & 0.01 p.u. \\
\hline Grid inductance $\left(\mathrm{X}_{\mathrm{g}}\right)$ & 0.12 p.u. \\
\hline
\end{tabular}

Table (B.3) Generator-side controller gains

\begin{tabular}{|c|c|c|}
\hline & Parameter & Value \\
\hline q-axis Current & $\mathrm{K}_{\mathrm{p}}$ & -0.04 \\
Controller & $\mathrm{K}_{\mathrm{i}}$ & 7.50 \\
\hline d-axis Current & $\mathrm{K}_{\mathrm{p}}$ & -0.04 \\
Controller & $\mathrm{K}_{\mathrm{i}}$ & 7.50 \\
\hline
\end{tabular}

Table (B.4) Grid-side controller gains

\begin{tabular}{|c|c|c|}
\hline & Parameter & Value \\
\hline q-axis Current & $\mathrm{K}_{\mathrm{p}}$ & 0.015300 \\
Controller & $\mathrm{K}_{\mathrm{i}}$ & 0.000365 \\
\hline d-axis Current & $\mathrm{K}_{\mathrm{p}}$ & 0.015300 \\
Controller & $\mathrm{K}_{\mathrm{i}}$ & 0.000365 \\
\hline
\end{tabular}

